\title{
Researchers' Attitudes and perceptions towards data sharing and data reuse in the field of Food Science and Technology
}

Remedios Melero. Instituto de Agroquímica y Tecnología de Alimentos-CSIC. Catedrático Agustin Escardino 7, 46980 Paterna, Valencia

Email: rmelero@iata.csic.es. $\underline{\text { https://orcid.org/0000-0002-1813-8783 }}$

Carolina Navarro-Molina. Instituto de Agroquímica y Tecnología de Alimentos-CSIC

Catedrático Agustin Escardino 7, 46980 Paterna, Valencia

Email: canamillo@gmail.com. https://orcid.org/0000-0003-0713-410

This work analysed the perception and practice of sharing, reusing and facilitating access to research data in the field of food science and technology. The study involved the coordination of a focus group discussion and an online survey. The lack of a data sharing culture, the fear of being scooped, and confusion between the concepts of the working plan and the data management plan were some of the issues that emerged in the focus group. Respondents' previous experience with sharing their research data has been mainly in the form of appendices to peerreviewed publications. The most important motivations for publishing research data were found to be facilitating the reproducibility of the research; increasing the likelihood of citations of the article; and compliance with funding body mandates. Legal constraints, intellectual property, data ownership, data rights, potential commercial exploitation and misuse of data were the main barriers to publishing data as open data. Citation in publications, certification, compliance with standards, and the reputation of the data providers were the most relevant factors affecting the use of other researchers' data. Being recent or recently updated, well documented, with quality metadata and ease of access were the most valued attributes of open research data.

Keywords: open research data, data sharing, ownership, data management, authors preferences, authors perception

\section{INTRODUCTION}

The term "research data" refers to quantitative or qualitative information collected by researchers in the course of their work, obtained from experimentation, observation, modelling, through surveys or interviews, or by other means, or created from existing data. Research data provide the necessary information to support or validate the 
results or conclusions of the investigation. Their publication and preservation facilitate their reuse, their validation and to support the reproducibility of the research.

To make the research data available, accessible, reusable, assessable and intelligible (Science as an Open Enterprise, 2012), we need not only to establish clear policies supporting open science, but also to promote changes in the practices and habits of researchers. New systems for recognition, rewarding and evaluation of open research practices should also be taken into consideration to change the whole science communication environment. Currently, these recognition systems are based mostly on the number and quality of publications and not on the efforts made to be an open scientist.

Open research data policies are important drivers, but implementation and compliance differs depending on their provenance and disciplinary approach. Institutional and funder policies are considered very important for social sciences and chemical sciences; however, in the field of economics, policies issued by a scientific society are considered more important (Schmidt, Gemeinholzer \& Treloar, 2016).

In Europe, the European Commission and the European Research Council (ERC), through the Horizon 2020 Framework Program, have supported open access to scholarly publications and to research data under the principle of "as open as possible, as closed as necessary" (European Commission, 2016). European policy is focused on turning Europe into a place where open science is the new paradigm for conducting research, and to making the results of publicly funded research freely available (Guedj D, 2015). The new EU Directive 2019/1024 on open data and the reuse of public sector information also includes research data and requires member states to adopt open policies on data obtained through publicly funded research (European Union, 2019).

Public and private research funding organisations and research institutions also increasingly require researchers to develop data management plans (see Sherpa Juliet directory). A Data Management Plan (DMP) describes the management of the life cycle of data gathered, processed and/or created in a project. It is a living document that identifies and describes issues such as the data gathering process, the metadata standards used in their description, and data preservation, while also reflecting changes or modifications made during the research project. In summary, the DMP provides comprehensive information on the data and the context in which they were created. There are numerous resources available to support the creation of a DMP, such as those created by the Digital Curation Centre (DCC), the Australian Research Data Commons (ARDC), or Data Archiving and Networked Services (DANS).

Data reuse practices are facilitated by aspects such as efficiency, perceived effectiveness, and the importance of developing the research (Gonçalves, 2017, Curty, 2017). However, problems arising from the interoperability of standards and formats, or a lack of understanding of intellectual property issues, may constrain their implementation (Wallis, 2013). 
Despite the benefits that sharing and reusing data can have for researchers (Costello, 2009, Piwowar, 2011; Michener, 2015, Wiley, 2018), both practices face technical barriers related to the management of data (Michener, 2015) and to social aspects associated with the attitudes and habits of researchers. Genomics, for example, is a field in which technology has overcome the barriers of distance and facilitated data sharing, but there are still other barriers arising from the human factor (resistance, competition, habits) that are slowing down such sharing (Fusi et al., 2018). In the field of public health, in addition to technical, economic and motivational difficulties that need structural solutions, there are also political, legal and ethical considerations that require international consensus to promote fluid data exchange (van Panhuis et al., 2014). Fecher et al. (2015) surveyed individual academic researchers across all disciplines on their handling of data, their publication practices, and motivators for sharing or withholding research data. The survey found that the main impediments to making data available were the need to publish a paper before sharing the data that supported it, and the efforts required to share them. $80 \%$ of respondents cited the fear that others could publish their data before them as a reason for these reservations, evidencing the need for training and information on how to share and reuse data. Fear of losing control over their data was the main reason for the reluctance; however, respondents said they would openly share their data if they had the power to decide how and when their data was reused, and by whom. A big driver for making data available to others was recognition-i.e., data citation.

Researchers' behaviour related to the exchange and use of data also varies between disciplines. According to one of the first studies carried out in this regard (Tenopir et al., 2011), researchers in atmospheric and environmental sciences and ecology expressed a willingness to share (87\%) their data. Most authors in other disciplines who participated in the study were also willing to share, but with significant differences among them; in particular, respondents in the fields of computer science and medicine were more reluctant. In biology, data discovery is fundamental and it is also the area where the highest percentage of shared data was reported (Stuart et al., 2018).

Researchers in the areas of engineering and computer science considered it very important to adhere to the FAIR data principles (Findable, Accesible, Interoperable and Reusable; Wilkinson, M., Dumontier, M., Aalbersberg, I. et al., 2016) for the advancement of their discipline, while researchers in earth sciences and economics supported the idea of adhering to the FAIR data principles, but with some reservations (Schmidt, Gemeinholzer, \&Treloar, 2016). Researchers in social sciences and political science tend to be influenced by their colleagues, so that data sharing is likely to become common practice if their community advocates and practices it (Zenk- Möltgen et al., 2018).

The Spanish National Research Council (CSIC, for its initials in Spanish) is the largest public institution in Spain dedicated to research and one of the most prominent in the European Research Area (ERA). CSIC operates a large number of major research centres where its scientific and technical research activity is generally conducted. Each of these centres is thematically integrated into one of the eight scientific areas of the 
CSIC, one of which is food science and technology

(https://www.csic.es/en/investigation/institutes-centres-units).

The aim of this study was to examine and analyse the perception and practice of sharing, reusing and facilitating access to research data in the field of food science and technology among researchers working at CSIC research centres. The study data was collected by means of a focus group discussion and an online survey. This is the first subject-oriented study performed at CSIC, and it could lead to further analysis in other research areas.

\section{METHODS}

\subsection{Focus group}

A focus group was organised to discuss topics related to the research data life cycle and the practice of creating data management plans (DMPs). The purpose of the discussion was to gather information about perceptions and awareness of the meaning of data management and data sharing, and attitudes toward research data reuse and sharing. The focus group (FG) was held in June 2018, with seven researchers from IATA-CSIC (Institute of Agrochemistry and Food Technology) with previous experience in applying for and conducting European research projects.

\subsection{Online Survey}

Based on information collected from previous studies (Berghmans, 2017; Schmidt et al., 2016; Tenopir, 2015; Teperek, 2018), a questionnaire was developed with 43 questions organised into seven content blocks (ANNEX A): demographic data; format, volume and storage of data; funding organisation; sharing and reuse of research data; reasons to share open data; obstacles to publishing research data in open access, and; citation, licensing and training.

The initial questionnaire was shared and tested with three researchers who gave us their opinion about the clarity of the questions. After the comments were received, the final version was developed using the Google Forms tool. Email addresses of senior scientists, scientific researchers, research professors, and postdoctoral fellows were retrieved from the websites of eight CSIC research institutes in food science, nutrition and agrochemistry. We collected 465 email addresses but 62 were found to have issues, resulting in a total of 403 researchers to be contacted. Emails were sent individually explaining the aim of the study with a link to the online survey. The questionnaire was available from July to October 2018, during which time three reminders were sent. It was not mandatory to answer all the questions. The survey data were exported to an Excel sheet for descriptive analysis and visual representation. The questions with Likert-type scales (extent of agreement/disagreement) and rating 
scales (very important/not at all important) with 5 or 4 points, respectively, were coded by assigning a value from lowest to highest. They were then grouped into four categories: barriers, motivators, conditions, and quality. A factor analysis was applied to identify which underlying factors were measured by the observed variables within these four categories. Then, a cluster analysis was applied to find, if any, groups of cases that could represent respondents as a whole. Both statistical techniques were performed using the statistics package SPSS v24. The Kaiser-Meyer-Olkin (KMO) statistic was used to to determine how suited the data were for factor analysis (sampling adecuacy), and indicates the proportion of variance in the variables that might be caused by underlying factors (values higher that 0.7 generally indicate that a factor analysis may be useful with the obtained data). Cronbach's alpha was used as a measure of reliability, or internal consistency. Cronbach's alpha outlines if the test you have designed is accurately measuring the variable of interest.

\section{RESULTS AND DISCUSSION}

\subsection{Focus group outputs}

Seven researchers from the CSIC Institute of Agrochemistry and Food Technology participated in the focus group. The session lasted approximately 1.5 hours and participants discussed two issues raised by the facilitator:

1. What do you understand a data life cycle to be?

2. What do you understand a data management plan (DMP) to be? Have you had any experience creating DMPs?

Out of these two topics the following issues emerged. Each issue is followed by a brief summary based on the group's comments, and some perceptions from the moderator:

Issue 1: Meaning of the terms "data life cycle" and "research data"

- The participants believed it necessary to clearly define what is meant by "data life cycle", since it can be approached from two perspectives: the research process that starts in a specific project and ends when the results are published; or the time during which data are gathered and become ready to use.

Moderator's perception: Lack of understanding of the concepts.

- It is also necessary to clarify what exactly is meant by "data" in order to define more precisely what their life cycle is.

Moderator's perception: Definition of data not clear.

Issue 2: Publication of research data 
- The option of publishing raw research data was unknown to participants.

Moderator's perception: New venues for data publication unknown.

- Doubts were raised about the usefulness of publishing data, considering that all the information has already been used in the published articles.

Moderator's perception: Lack of culture of acceptance of open raw data before publication.

Issue 3: Data lifespan

- Participants considered it necessary to determine data lifespan to be able to preserve data correctly during their life cycle. Data are considered to be still useful as long as current technology has not surpassed the method originally used to collect them. Another concern, beyond their obsolescence, was with the validity of data in a different context. There were also participants who felt that data lose their validity once a research project is finished.

Moderator's perception: The obsolescence of research data is not always clear.

Issue 4: Dissemination, sharing and publication of data

- The idea of data sharing was not widely accepted because data are created/obtained within the context of a project that renders them understandable; however, outside that context they could be misinterpreted or misunderstood. In order to avoid this, sharing data requires a previous debugging and description of how the data were collected, treated, formatted, analysed, etc., entailing an increased workload.

Moderator's perception: Fear of misinterpretation hinders data sharing.

- Data are collected/generated for the purpose of publication, but not for sharing and reuse.

Moderator's perception: Lack of culture of data sharing.

- Participants thought that information is already being shared once outputs are published, whether through publications, conferences, etc.

Moderator's perception: Publishing is misunderstood as being the same as sharing.

- Data sharing could be more easily assumed by the future generation of researchers, while the current generation continues with the traditional model in which "sharing" is done after publication and not before. There is also a resistance 
to data sharing due to the hard work involved in obtaining the data, from which others would be able to benefit without any effort.

Moderator's perception: Reluctance, fear of being scooped/copied.

Issue 5: Data Management Plans

- Participants said they have never created a Data Management Plan associated with their projects. Usually, they design a work plan to achieve their project research aims.

Moderator's perception: Confusion about the difference between a work plan and a data management plan.

- Participants understood a DMP to be a document drawn up at the end of the research, when the outputs are already available, as a final report rather than a living document drafted during the project.

- Participants agreed that DMPs should contain a description of the conditions for obtaining the data, data formats and data licensing. They also pointed to the importance of following international standards and formats, although there was some concern about the additional workload that this represents.

Moderator's perception: Standardisation/formatting of data means more work for researchers.

\subsection{Descriptive analysis}

\subsubsection{Survey-Block 1: Demographic data}

We sent 403 emails with the link to the online survey and received 101 responses (25\%), 57 were from women and 44 from men, in the following age ranges: $26-35$ years (3\%), 36-45 (21\%), 46-55 (50\%), 56-65 (24\%), and older than 65 (2\%). The respondents worked in the following food science and technology disciplines: food safety (11.4\%); Physical properties of food (4.2\%); chemical properties of food (7.2\%); biotechnology (14.4\%); microbiology (12.9\%); nutrition (8.4\%); functional foods (17.5\%); phytochemistry (5.3\%), modelling (2.3\%); genomics and proteomics (8\%); preservation (7.2\%); and sensory analysis (1.1\%).

\section{2.2 Survey-Block 2: Format, volume and storage of data}

Formats of research data used or created by researchers in their most recent project were textual, numerical, and images, while audio-visual formats were almost nonexistent (Figure 1). As was expected given the working areas concerned, the most 
common types were experimental data (53\%), followed by Observational or empirical (21\%), Reference or canonical (12\%), Derived or compliled (10\%) and Simulation (4\%).

Figure 1: Types and formats of research data used or created as part of the researcher's last project

In relation to the volume of data collected as part of the most recent research project, files were mostly small to medium size, although the "I don't know" response represents nearly $23 \%$ of total answers to this question, suggesting that volume does not represent a limitation or they are not aware of it (Figure 2a and $2 b$ ).

Figure 2: File size (a) and volume of data (b) collected as part of the researcher's last project

The preferred location used to store data files (Figure 3) is their personal computer despite the risk this option represents. Worthy of note is the minimal use of cloud services to store data files. Backups were performed on personal computers $163 \%$ performing one backup and $37 \%$ performing two), although some respondents said they lost some files during the past year (13\%).

Figure 3: Storage of data files

On the question of how long data should be stored, the largest proportion of respondents considered that most data files should be stored indefinitely (35\%), followed by $5-10$ years (26\%), $1-5$ years (17\%) and more than 10 years $(16 \%)$.

\subsubsection{Survey- Block 3: Funding source and data ownership}

According to the survey data, the biggest source of funding for research projects was the Spanish government (57\%), followed by corporate private/commercial organisations based on agreements or R\&D contracts with businesses in the sector (21\%), regional research funding from projects funded mainly by the European Commission (17\%); funding by their own institution accounted for $3 \%$, while $2 \%$ were funded by a charity or other third party.

It should be noted that when respondents were asked about their awareness of funding requirements for FAIR data, the most common response was "I don't know" (>50\%), and when they were asked whether the primary funding agency requires a data management plan, $60 \%$ said they did not while $38 \%$ said they did not know. This reflects 
a lack of awareness about how to make data findable, accessible, interoperable and reusable and/or about the funders' requirements for data management plans, despite the fact some respondents were working under the H2020 Open Research Data Pilot. This reveals a lack of awareness of their funder's requirements for research data.

Intellectual property and data ownership are issues researchers often misunderstand and misinterpret, and many do not even know how to respond to questions about who owns their data. Indeed, when asked who they thought the research data belonged to before and after publication, respondents offered very different answers, with $40 \%$ more respondents assigning ownership to the publisher after publication. This situation of ignorance about who owns research data is a very widespread problem if we consider the previous literature (Stuart et al., 2018).

\section{Figure 4: Who owns research data}

Misunderstandings could also arise in relation to what is meant by data when a paper is submitted. Authors might think of data as referring to tables, figures, or images, rather than to the raw data they represent. Authors might not be aware that when a publisher is assigned copyright over a paper, that copyright does not extend to the underlying raw data that support the results or the paper. On the other hand, it was surprising to find that some respondents attributed data ownership to the funder, because, in general, grant agreements do not have clauses regarding ownership but only regarding dissemination and data sharing.

\subsubsection{Survey-Block 4: Sharing and reuse of research data}

There is no doubt that open data is important in terms of research progress, science communication (public education and information, supporting applications of science to societal problems), and technology and knowledge transfer (Figure 5). This response might be obvious, however what respondents say is not always what they practice.

Figure 5: How important is open data in your community?

This behaviour, whereby data sharing is understood but is not translated into action, has also been described previously (Fecher et al., 2015).

More than $50 \%$ of respondents said they shared any or all of the research data used or created as part of their last research project directly with others (i.e., person-toperson); however, only $24 \%$ reuse data shared directly by others (i.e., person-toperson). 
Respondents rated the importance of data sharing before and after publication with other colleagues from different institutions or with the public at large (Figure 6) considerably higher after publication. The idea that making data publicly available before publication could jeopardize their future outputs could be the one of the main reasons for this.

Figure 6: Experience of sharing data supporting the researcher's paper before and after publication

Nearly $50 \%$ of respondents were aware of data repositories, but only $29 \%$ have used them to deposit datasets. Respondents were willing to directly share data collected during a research project; however, only $24 \%$ said they had used data shared by others. This might be related to a lack of trust in the data of others, or a lack of familiarity with the practice.

When asked what they have done with research data used or collected as part of their last research project, $62 \%$ of respondents said they shared them directly with researchers working on the same research project in a research collaboration, $22 \%$ directly with partner projects; very few (3\%) shared them directly with researchers not working on the same research project whom they did not know personally (see Table 1). This lack of trust and the fear that data may be misinterpreted or misused are attitudes also described in other fields, such as geophysics (Tenopir et al., 2018) and other disciplines (Fecher et al., 2016).

Most respondents (69\%) believe that a lot of effort is required to make their research data reusable by others (Table 1). This is a significant barrier to the reuse of research data. Familiarity with metadata, archiving venues, rights and licensing, or with how to create a data management plan is necessary for the production of FAIR data and deserves attention. Recognition of this effort (learning about metadata, archiving venues, IP issues, licensing, etc.) could transform this barrier into a motivation (Schmidt et al., 2016).

Respondents were asked to state their agreement or disagreement with different statements regarding the conditions for allowing other researchers to reuse their data (Figure 7). Acknowledgement, recognition, citation, collaboration and feedback from data users were the most commonly statements selected by respondents. Recovery of part of the cost of data acquisition does not seem as important when exchanging data is driven by prestige and reputation rather than money (Fecher, 2015, 2017).

Figure 7: Agreement/disagreement with statements related to conditions for using other researchers' data 
Citation in formal venues, certification, compliance with guidelines and standards, and the reputation of the data providers are the most important factors related to the use of other researchers' data . Regarding factors for determining whether to use others' data (Figure 8), more than $90 \%$ of respondents identified aspects related to the documentation and metadata provided to explain how the data were developed and formatted as important or very important. The provenance and reputation of data providers were also important factors in deciding on their reuse.

Figure 8: Factors for determining whether to use other researchers' data

\section{2.5 Survey-block 5: Reasons for using and sharing open data}

The most common situation in which respondents have previously shared their research data $(66 \%)$ has been as an appendix to a peer-reviewed research publication (journal or book), followed by a standalone peer-reviewed data publication (23\%), and archiving in a data repository (17\%).

Figure 9: Important motivators for publishing data as open data

All of the reasons for sharing data presented in the survey were identified by most respondents as important or very important, particularly those related to policy compliance (funders, institutions or publishers, see Figure 9). Conversely, when respondents were asked whether they were familiar with funders' expectations for FAIR data and funder policy requirements the response rate were low, $12 \%$ and $4 \%$ respectively.

Figure 10. Researchers' attitudes to using and sharing data

Figure 10 presents survey data regarding respondents' agreement or disagreement with certain conditions for reusing and sharing research data. Ease of access, sharing with some conditions on access, and proper citation when datasets are used were the top three conditions selected by respondents. Researchers would not share all their data in data repositories without restrictions of use; however, paradoxically, they would be willing to reuse others' data if they were easy to access. Citation of datasets when they are reused was an important issue, as seen previously. In summary, data providers do not want to lose control of who is able to access and reuse their data, but are open to new collaborations as a result of sharing research data. This same question was asked in a survey distributed to members of the American Geophysical Union (Tenopir et al., 2018); our results are qualitatively in agreement with this previous study, although 
quantitatively there are some differences in the percentages of respondents who disagreed with most of the statements except for the importance of citation.

Figure 10: Agreement/disagreement with statements related to sharing scientific data

The most important attributes of open research data identified by respondents were: data should be recent or updated, well documented with quality metadata to facilitate their interpretation, easily accessible but potentially protected or restricted in relation to their use (Figure 11)

Figure 11: Most important attributes of open research data

The most important benefits of publishing research data together with the article were rated as follows: facilitates reproducibility of research (62.4\%); article is more likely to be cited (54.5\%); compliance with funding body mandates $(52.5 \%)$; more possibilities for collaboration (49.5\%); compliance with journal or publisher requirements (38.6\%); data reuse $(37.6 \%)$; article is more likely to be accepted for publication $(32.7 \%)$; encourages other researchers to make their data publicly available (32.7\%); research aggregation (e.g. for meta-analysis, $29.7 \%$ ). These benefits are directly related to the researchers' own activities and rewards, rather than to changing the way research data is shared.

\subsubsection{Survey-block 6: Barriers}

Legal constraints, intellectual property, data rights, potential commercial exploitation and misuse of data are the main barriers to publishing data as open data (Figure 12). A lack of trust and misunderstandings about data ownership are the main factors behind these barriers. However, these barriers could be overcome by the establishment of effective data management and the promotion of best practices by policymakers and academic institutions.

Figure 12. Barriers for publishing data as open data.

Poor quality of data or metadata that could lead to a misinterpretation or misuse of data are also obstacles to the use of research data .Lack of access to data generated by other researchers was also mentioned as a major impediment to the progress of science (Figure 13).

Figure 13: Views on the use of scientific research data 
Formats, the time needed to understand how to interpret data, and how to access data are also major obstacles identified by respondents (Figure 14).

Figure 14: Significant obstacles to accessing and reusing data for research work

\subsubsection{Survey block 7: Miscellaneous (citation, licence types, and training)}

There is a growing need to cite research data that are not included in traditional publishing venues, but that have been shared directly (i.e., person-to-person sharing) or indirectly (downloaded from a repository). However, the culture of sharing, using and citing research data has not grown as quickly as desired. Standards for citation exist, but awareness of those standards appears to be poor:

- There are no agreed standards for citing research data in my field (62\%);

- There are agreed standards for citing research data in my field, and most researchers follow them (21\%);

- There are agreed standards for citing research data in my field, but most researchers do not follow them (6\%);

- There is no need for standards for the citation of research data (1\%).

When asked about the licences that the researchers would use to distribute and share their data, only $8 \%$ indicated CC BY; $27 \%$ indicated CC BY-NC; $19 \%$ identified CC BY-NCND, and 39\% responded "I don't know". Lack of knowledge about the meaning of licences might be the reason behind these results, especially because one of the motives for data sharing is the creation of potentially new results/outputs, which means that the use of restrictive licences makes no sense.

More than $70 \%$ of respondents recognized the need for training in several areas: copyright and intellectual property (88\%); the use of data repositories and open access (84\%); storing and backing up data (81\%); sharing data (74\%); creating metadata for research data (74\%), and; ethics and consent for data creation (72\%).

In relation to who should provide this training, the most popular response was a professional in data management (38.6\%), followed by the research support unit(s) (26\%), and the library (16.5\%).

\subsection{Factor and cluster analyses}

As mentioned in the section on methodology, questions with rating or Likert-type scales in which respondents expressed their preference/importance or agreement/disagreement were subjected to a factor analysis to assess the correlations between variables, reduce their number and explain the biggest variance with the 
smallest number of factors. Factor variables were used to group individuals in a cluster analysis to identify similarities among members of the same group.

The variables that have been taken into account responded to four categories according to the information gathered: (1) motivators for using, sharing and publishing research data; (2) barriers to sharing research data; (3) conditions for accessing and reusing research data; and (4) aspects related to the quality of research data and metadata. The results obtained under these four categories are discussed in the following sections.

\subsubsection{Questions related to motivations for sharing and publishing research data}

The category grouping survey questions associated with the importance of open data and the motivators for sharing research are shown in Table 2.

Table 2. Importance of open data and the motivators to share research.

In the factor analysis a rotated matrix with the factor loadings was produced. Only factors higher than 0.6 were considered, resulting in a reduction to three factors that accounted for $62.8 \%$ of the variance, and a value of 0.748 in the KMO and Bartlett's Test. The importance of data sharing and the motivation for it are represented by these three factors. Cronbach's alpha, which measures the degree of reliability, ranged between 0.7 and 0.84 , confirming the scale adopted.

Factor 1 grouped items V71, V72, V70, V69 and V64 (Cronbach's alpha $=0.743$ ), involving aspects related to philanthropic issues: Dissemination and promotion of research, and personal commitment to open data.

Factor 2 grouped items V65, V68, V66 and V67 (Cronbach's alpha $=0.854$ ), related to aspects to support open data motivated by institutional, funder or publisher mandates.

Factor 3 grouped items V17, V18, V16 and V15 (Cronbach's alpha $=0.743$ ), related to more pragmatic aspects: the importance of data for technology transfer and to support applications of science to societal problems.

The cluster analysis placed the respondents into four groups. Cluster 1 grouped 38 individuals, comprising researchers with high scores for the philanthropic motivators (Factor1). Cluster 2 grouped 45 individuals who assigned a high mean value to all three factors. Clusters 3 and 4 grouped 7 and 11 individuals with low mean values for Factor 2 and Factor 1, respectively. In summary, more than three quarters of respondents agreed on the importance of open data to their commitment with society and for compliance with mandates

\subsubsection{Questions related to barriers to sharing research data}


The factor analysis of questions classified under the barriers category (Table 3) produced seven factors. The first three factors accounted for $50 \%$ of the variance with a KMO and Bartlett's Test score of 0.785 . The other factors did not result in a reduction of variables. These factors represent barriers to publishing, accessing and reusing research data.

Table 3. Items classified under barriers category

Factor 1 grouped items related to legal issues (IP, legal responsibility, misuse).

Factor 2 included aspects associated with understanding the meaning of the data (content and metadata).

Factor 3 encompasses aspects related to access to data and understanding their terms of use, licensing and citation. Cronbach's alpha, which measures the degree of reliability, ranged between 0.88 and 0.86 , confirming the scale.

The cluster analysis performed with the previous three factors produced three groups that accounted for $50 \%$ of the variance. Cluster 1 comprised 43 participants who scored all three factors highly, especially Factors 1 and 2, with mean values greater than 4 out of 5 points. Cluster 2 grouped individuals who stressed the importance of metadata quality and the specification of what and how research data were gathered to facilitate their understanding. Cluster 3 comprises 15 individual who considered legal issues related to data to be very important.

\subsubsection{Questions related to how to access and reuse of research data: Conditions}

The category that groups items of the questions associated with the conditions under which they would share their data or facilitate their access, are displayed in Table 4.

Table 4. Items associated with which conditions would they share their data or would facilitate their access

The factor analysis produced two factors that accounted for $58 \%$ of the variance (KMO and Bartlett's test $=0.642$ ).

Factor 1 grouped items : V47, V45, V50, V44, and V48 (Cronbach's alpha $=0.825)$

Factor 2 grouped items: V74, V73, V77, V75, and V78 (Cronbach's alpha $=0.789$ )

The first factor comprised items associated with permissions, and control by the creator for the reuse of datasets. As has been noted in the previous sections, fear of misuse is another reason why data creators may be reluctant to share their data. Factor 2 refers 
to the ease/willingness with which they could access or deposit datasets in centralised repositories.

The cluster analysis resulted in three clusters of 25,63 , and 11 participants, respectively; Individuals included in cluster 1 seem not to rely on permissions for the use of datasets and they have a moderate opinion regarding facilitating access to their data through centralised repositories. Clusters 2 and 3 exhibit a moderate and similar attitude respect to Factor 1 and Factor 2.

\subsubsection{Questions related to the quality of datasets}

In this section, issues affecting the quality of the metadata and attributes of the research data (Table 5) have been taken into account based on the degree of importance assigned to them by the respondents.

Table 5. Items affecting the quality of the metadata and attributes of the research data

The factor analysis of questions classified in this category (Table 5) produced five factors that accounted for $63 \%$ of the variance with a KMO and Bartlett's Test score of 0.741 , related to the use of other researchers' data depending on their characteristics.

Factor 1 grouped items V85, V84 V83, and V86 (Cronbach's alpha $=0.854$ ), related to the need of a well definition of data and metadata.

Factor 2 grouped V55, V56, and V54 (Cronbach's alpha $=0.827$ ), associated with the use of recognised standards for data and metadata.

Factor 3 grouped items V53, V51, and V52 (Cronbach's alpha $=0.716)$, associated with the reliability of the data providers (reputation and trust).

Factor 4 grouped items V87, V82, and V81 (Cronbach's alpha $=0.680$ ), related to unrestricted access to research data.

Factor 5 grouped items V58, V59, and V57 (Cronbach's alpha $=0.703$ ), related to accreditation and certification of data shared by third parties.

The cluster analysis produced four groups with 4, 50, 46, and 1 individual, respectively. If we consider Factors 1 and 4 formed by outliers, we are left with two groups with approximately the same number of people whose attitudes follow the same trend with respect the five dimensions except for some individuals in cluster 3 who rated Factor 2 
items (quality of content and metadata) more highly. Almost all respondents agreed on the importance of access, reputation and certification of data and metadata.

\section{CONCLUSIONS}

In the existing literature there are works related to the habits and attitudes of researchers regarding sharing, use, access and reuse of research data, in areas such as psychology, sociology, physics, astronomy, and also from a multidisciplinary perspective. This study focuses on an important field not only from the research point of view, but also in terms of the importance that data could have in other fields like health, nutrition, and consumer attitudes. Reliable data sharing could therefore represent an important contribution to the scientific community and to society in general. Reasons given by researchers for data sharing reveal that many view it as a means of promoting and disseminating research results, although mandates play an important role in their participation. A lack of awareness of legal aspects related to data and a reluctance to share data for fear of losing exclusive control over it are problems that have emerged in various studies, while a lack of knowledge of data management constitutes a barrier to data sharing. All this points to the need for ongoing training and education in the emerging field of data management to make authors aware of the potential of sharing data safely and legally. There is also a need to create institutional policies on research data rather than just on publications, and to ensure their terms are understood, and the work of data managers and librarians should not be based voluntary but supported by academic authorities. Another very important issue to explore is how the work involved in sharing and managing research data is encouraged and rewarded. Some of these aspects have been stated before in other disciplines, that might lead to conclude they are not discipline-specific but something related with intrinsic research habits that need a cultural change to create a real data sharing ecosystem.

This study can serve not only as a snapshot of the attitudes of a particular scientific community but also as a guide for the types of measures needed to accompany the provision of services, training, incentives and recognition for researchers, that could be extrapolated to any other communities.

\section{Acknowledgements}

The authors would like to thank the Spanish Ministry of Science, Innovation and Universities for granting the national project code RTI2018-094360-B-I00. The authors also wish to thank Amparo Tárrega for her valuable advice and help with the statistical analyses.

\section{References}


- Australian Research Data Commons. (2018). https://ardc.edu.au/ Accessed 03 September 2019.

- [dataset] Berghmans, S., Cousijn, H., Deakin, G., Meijer, I., Mulligan, A., Plume, A., de Rijcke, S., Rushforth, A., Tatum, C., van Leeuwen, T.\& Waltman, L. (2017). Open Data: the researcher perspective. Survey and case studies. Mendeley Data, v1. http://dx.doi.org/10.17632/bwrnfb4bvh.1\#file-795c8917-7e28-4eb7-8bc4791d96e9743f

- Costello, M.J. (2009). Motivating online publication of data. BioScience, 59(5), 418-27.

- Curty, R.G., Crowston, K., Specht, A., Grant, B.W.\& Dalton, E.D. (2017). Attitudes and norms affecting scientists' data reuse. PLOS ONE, 12(12), e0189288. https://doi.org/10.1371/journal.pone.0189288

- Data Archiving and Networked Services. https://dans.knaw.nl/en/frontpage?set language=en .Accessed 03 September 2019.

- Digital Curation Center. http://www.dcc.ac.uk/ Accessed 03 September 2019.

- European Commission.https://europa.eu/european-union/about-eu/institutionsbodies/european-commission es. Accessed 03 September 2019.

- European Research Area. https://ec.europa.eu/info/research-andinnovation/strategy/era es. Accessed 03 September 2019.

- European Research Council (ERC).https://erc.europa.eu/Accessed 03 September 2019.

- European Union. https://europa.eu/european-union/index es. Accessed 03 September 2019.

- Fecher, B., Friesike, S., Hebing, M., Linek, S.\& Sauermann, A. (2015). A Reputation Economy: Results from an Empirical Survey on Academic Data Sharing. DIW Discussion Papers, 10.2139/ssrn.2568693. https://ssrn.com/abstract=2568693

- Fecher, B., Friesike, S., Hebing M.\& Linek, S. (2017). A reputation economy: how individual reward considerations trump systemic arguments for open access to data. Palgrave Communications, 3,17051. https://dx.doi.org/10.1057/palcomms.2017.51

- Fusi, F., Manzella, D., Louafi, S.\& Welch, E. (2018). Building Global Genomics Initiatives and Enabling Data Sharing: Insights from Multiple Case Studies. OMICS, 22(4),237-247. doi: 10.1089/omi.2017.0214.

- Gonçalves-Curty, R., Crowston, K., Specht, A., Grant, B.W.\& Dalton, E.D. (2017). Attitudes and norms affecting scientists' data reuse. PLOS ONE, 12(12),e0189288. https://dx.doi.org/10.1371/iournal.pone.0189288

- Guedj, D.\& Ramjoué, C. (2015). European Commission Policy on Open-Access to Scientific Publications and Research Data in Horizon 2020. Biomed Data Journal, 1(1),1114. http://dx.doi.org/10.11610/bmdj.01102

- Institute of Agro Chemistry and Food Technology. https://www.iata.csic.es/es. Accessed 03 September 2019.

- Michener, W.K. (2015). Ecological data sharinG. Ecological Informatics, 29, 33-44. http://dx.doi.org/10.1016/j.ecoinf.2015.06.010

- Piwowar, H.A. (2011). Who shares? Who doesn't? Factors associated with openly archiving raw research data. PLoS ONE, 6(7),e18657 https://dx.doi.org/10.1371/journal.pone.0018657 
- Schmidt, B., Gemeinholzer, B. \& Treloar, A. (2016). Open Data in Global Environmental Research: The Belmont Forum's Open Data Survey. PLOS ONE, 11(1), e0146695. https://doi.org/10.1371/journal.pone.0146695

- SHERPA JULIET directory. http://sherpa.ac.uk/romeo/index.php?la=es\&fIDnum=|\&mode=simple Accessed 03 September 2019.

- SHERPA RoMEO. Publisher copyright policies \& self-archiving. http://www.sherpa.ac.uk/romeo/index.phpAccessed 03 September 2019.

- Spanish National Research Council. https://www.csic.es/ Accessed 03 September 2019.

- Stuart, D., Baynes, G., Hrynaszkiewicz, I., Allin, K., Penny, D., Lucraft, M.\& Astell, M. (2018). Whitepaper: Practical challenges for researchers in data sharing. https://dx.doi.org/10.6084/m9.figshare.5975011.v1

- Tenopir, C., Allard, S., Douglass, K., Aydinoglu, A.U., Wu, L., Read, E., et al. (2011). Data sharing by scientists: Practices and perceptions. PloS One,6(6), e21101. https://doi.org/10.1371/journal.pone.0021101

- Tenopir, C., Dalton, E.D., Allard, S., Frame, M., Pjesivac, I., Birch, B., et al. (2015) Changes in Data Sharing and Data Reuse Practices and Perceptions among Scientists Worldwide. PLoS ONE, 10(8), e0134826. https://doi.org/10.1371/journal.pone.0134826

- Tenopir, C., Christian, L., Allard, S.\& Borycz, J. (2018). Research data sharing: Practices and attitudes of geophysicists. Earth and Space Science, 5, 891- 902. https://doi.org/10.1029/2018EA000461

- Teperek, M., Krause, J., Lambeng, N., Blumer, E., van Dijck, J., Eggermont, R.\& BusseWicher, M. (2018, February 25). Survey: research data management practice. https://osf.io/54em6/Accessed 03 September 2019.

- The Royal Society. Science as an open enterprise. https://royalsociety.org/topicspolicy/projects/science-public-enterprise/ Accessed 03 September 2019.

- Van-Panhuis, W.G., Paul, P., Emerson, C., Grefenstette, J., Wilder, R., Herbst, A.J., Heymann, D.\& Burke, D.S. (2014). A systematic review of barriers to data sharing in public health. BMC Public Health, 14,1144. https://dx.doi.org/10.1186/1471-2458-14$\underline{1144}$

- Wallis, J.C., Rolando, E.\& Borgman, C.L. (2013). If We Share Data, Will Anyone Use Them? Data Sharing and Reuse in the Long Tail of Science and Technology. PLOS ONE 8(7), e67332. https://doi.org/10.1371/journal.pone.0067332

- Wiley, C. (2018). Data Sharing and Engineering Faculty: An Analysis of Selected Publications. Science \& Technology Libraries, 37(4), 409-419. https://dx.doi.org/10.1080/0194262X.2018.1516596

- Wilkinson, M., Dumontier, M., Aalbersberg, I. et al. (2016). The FAIR Guiding Principles for scientific data management and stewardship. Sci Data 3, 160018, https://dx.doi.org/10.1038/sdata.2016.18

- Zenk-Möltgen, W., Akdeniz, E., Katsanidou, A., Naßhoven, V.\& Balaban, E. (2018). Factors influencing the data sharing behavior of researchers in sociology and political science. Journal of Documentation, 74(5),1053-1073. https://dx.doi.org/10.1108/JD-09$\underline{2017-0126}$ 


\section{FIGURES}

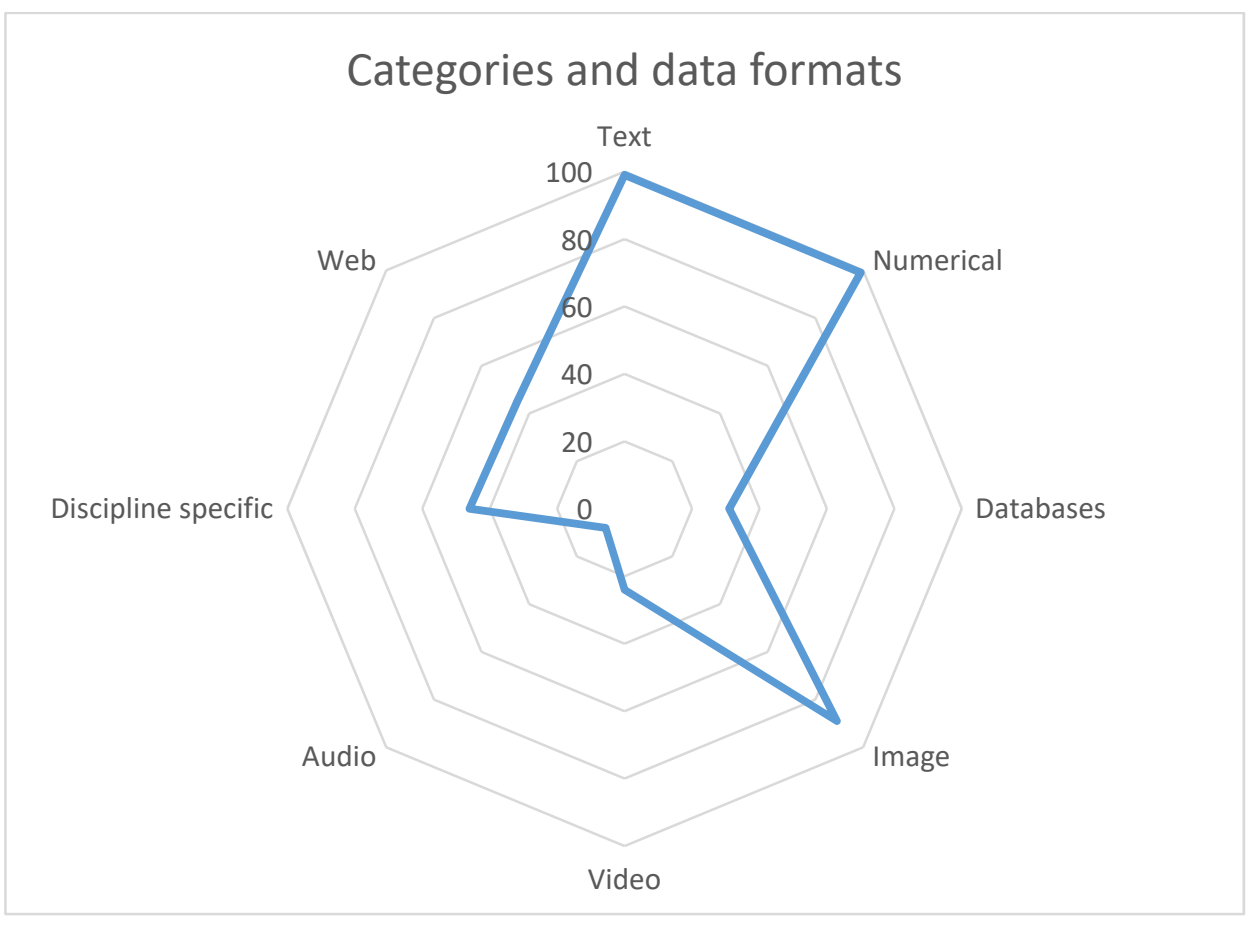

Figure 1. Formats of research data used or created during last research project. 
(a)

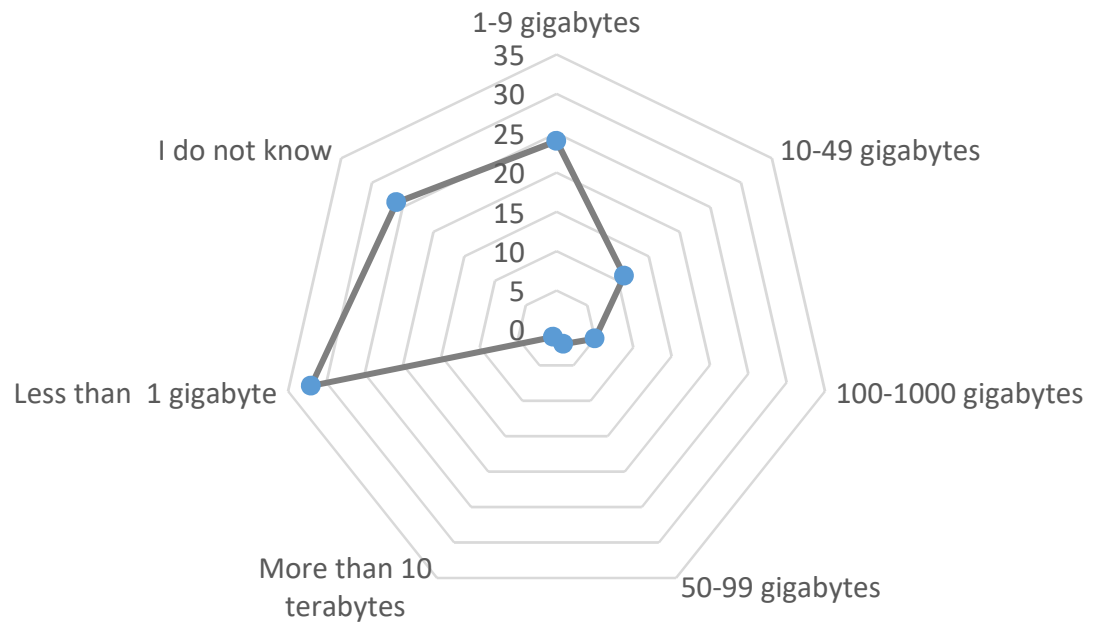

(b)

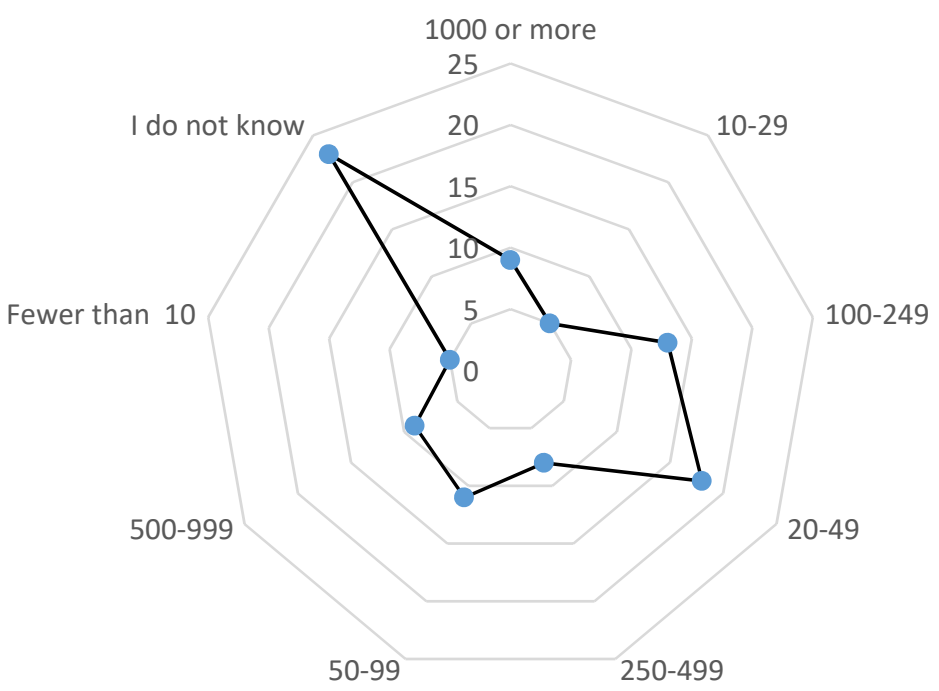

Figure $\mathbf{2 b}$. File size (a) and number of data files (b) produced as part of las research project. 


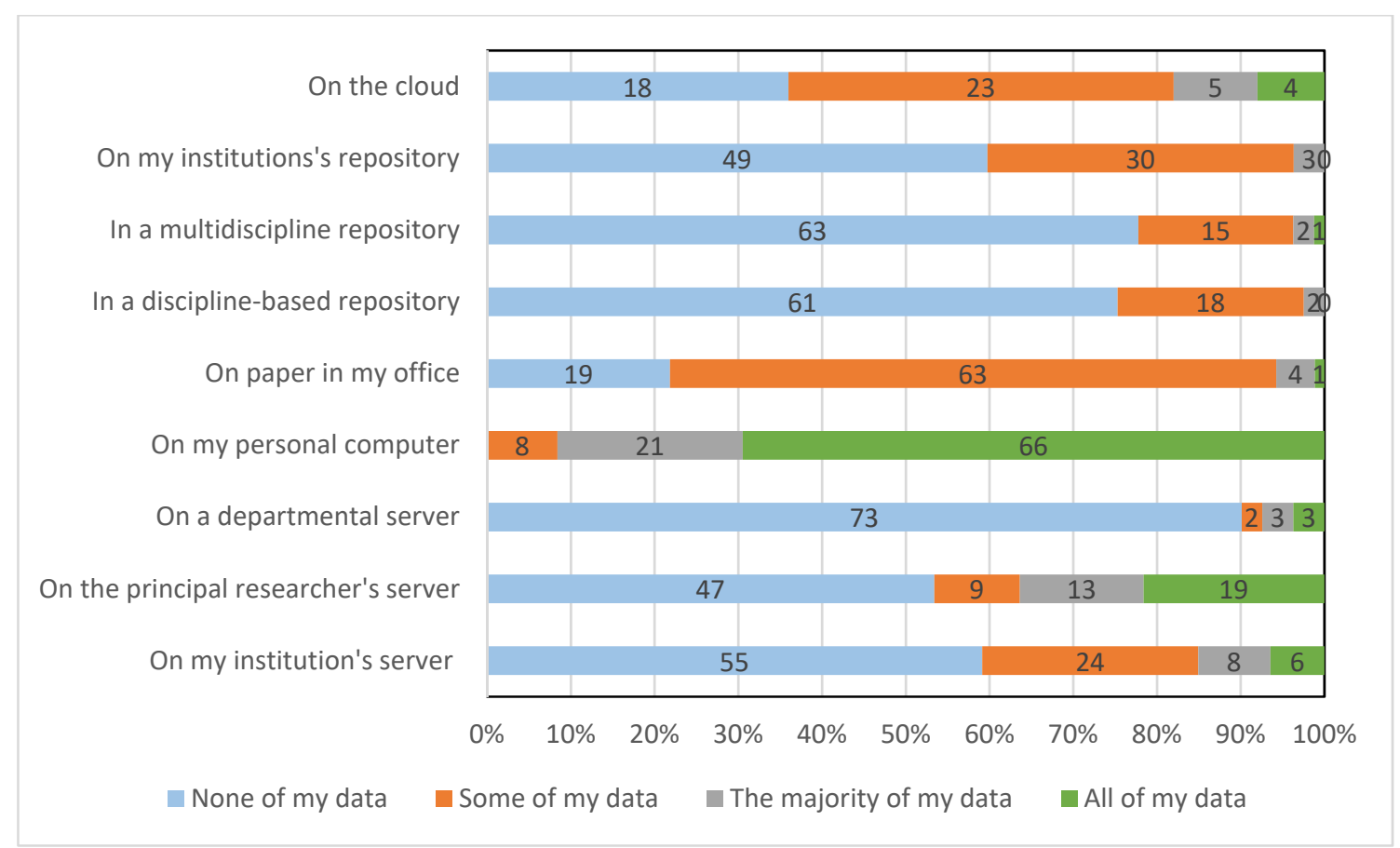

Figure 3. Locations currently used to store your own data (number of responses displayed in the bars). 


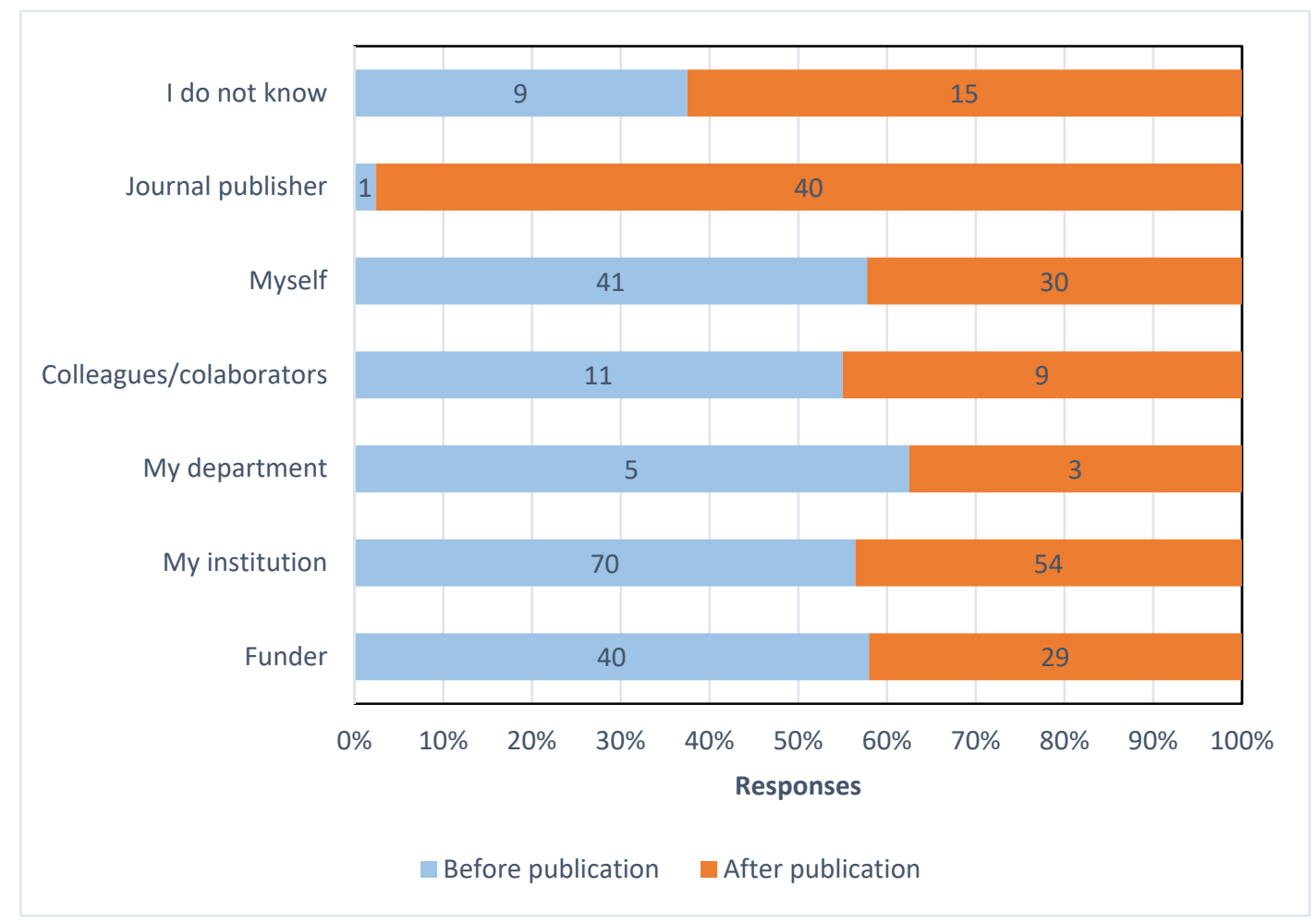

Figure 4.Who owns research data before and after (number of responses displayed in the bars). 


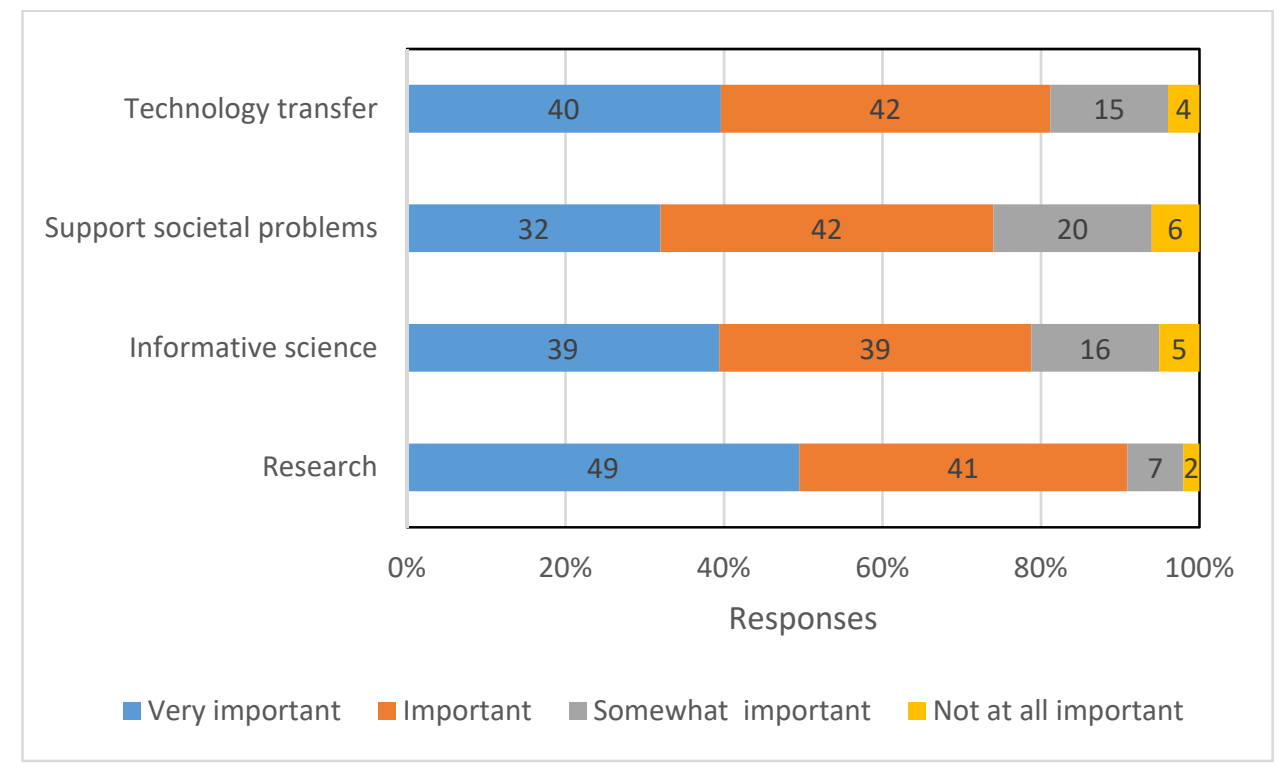

Figure 5. Importance of open data to different aspects (number of responses displayed in the bars). 


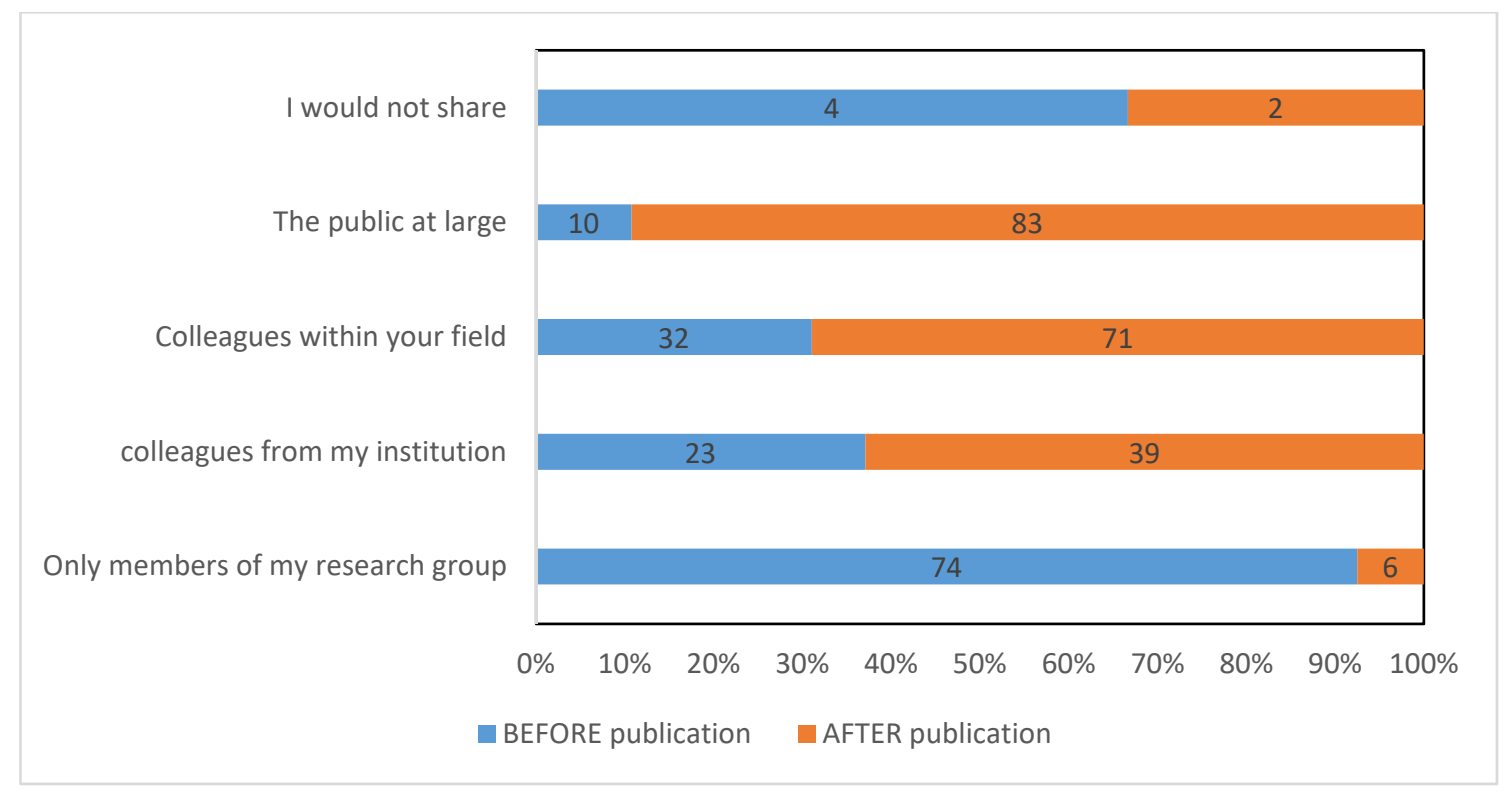

Figure 6. Experience sharing your data underlying your paper before and after publication (number of responses displayed in the bars). 
The data provider, provides and accepts an agreement for its use

There is a mutual agreement on reciprocal sharing of data Legal permission for data use is obtained

The data provider is given a complete list of all products that make use of the data, including articles, presentations, educational materials, etc.

Reprints of articles that make use of the data must be provided to the data provider

The results based (at least in part) on the data could not be disseminated without the data provider having the opportunity to review the results and make suggestions or comments, but approval not required

At least part of the costs of data acquisition, retrieval or provision must be recovered

The results based (at least in part) on the data could not be disseminated in any format without the data provider's approval.

Share facilitates the opportunity to collaborate on a project using the data

Citation of the data providers in all disseminated work making use of the data

Acknowledgement of the data providers in all disseminated work making use of the data.

Should be co-authorship on publications resulting from use of the data

$$
0 \%
$$

I do not agree
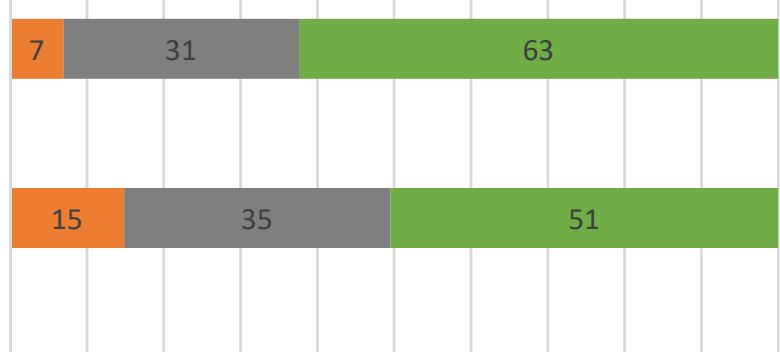

$19 \quad 33$
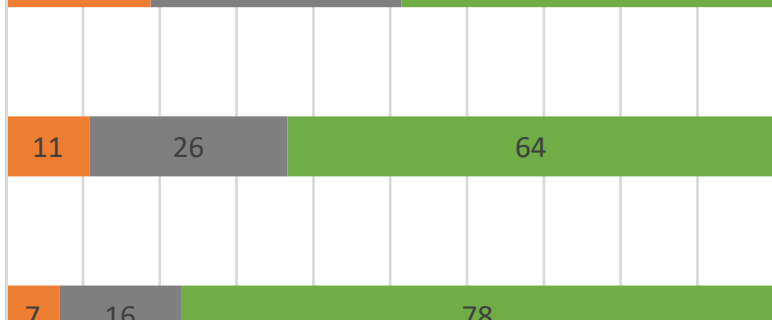

\begin{tabular}{l|l}
7 & 16
\end{tabular}

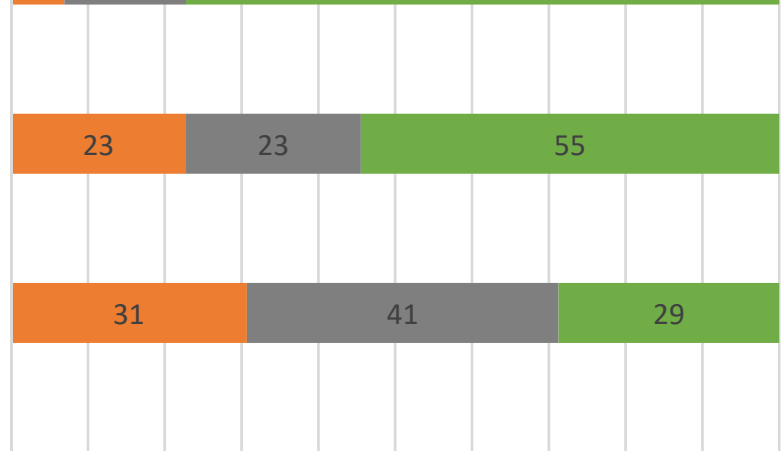

$23 \quad 22$
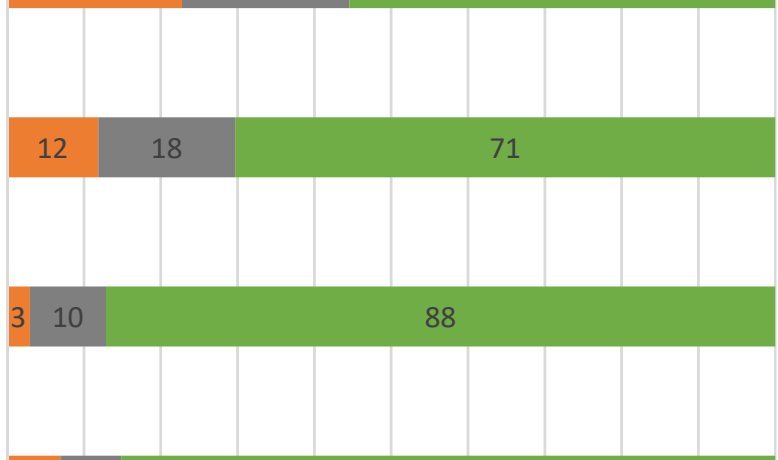

$7 \quad 86$

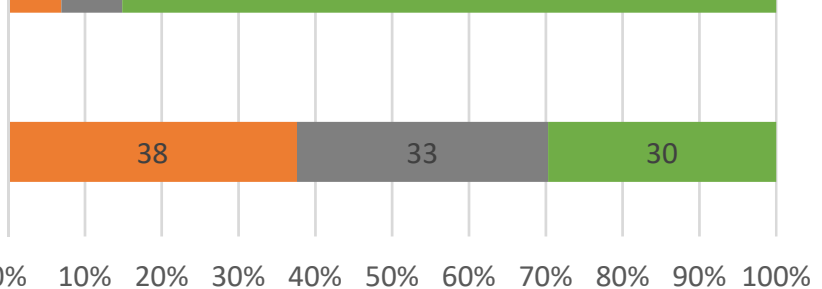

I am not sure $\quad$ I agree

Figure 7. Agreement/disagreement with several statements relate to conditions for use of others'data (number of responses displayed in the bars). 
Have been cited in a publication in the formal literature (journals, books, etc.)

Are commonly used by others

Are certified or accredited by a third party

Have good documentation and/or metadata

Comply with guidelines around collection and/or formatting

Are from a repository with a good reputation

Are from someone at an institute with a good reputation

Are from someone I DON'T know personally but who has a good reputation

Are from someone I know personally

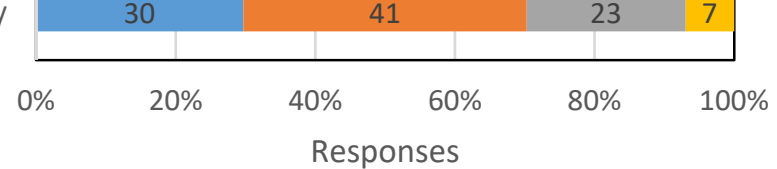

- Very Important $\quad$ Important

- Somewhat important

Unimportant

Figure 8. Factors that affect the use other's research data. (number of responses displayed in the bars). 


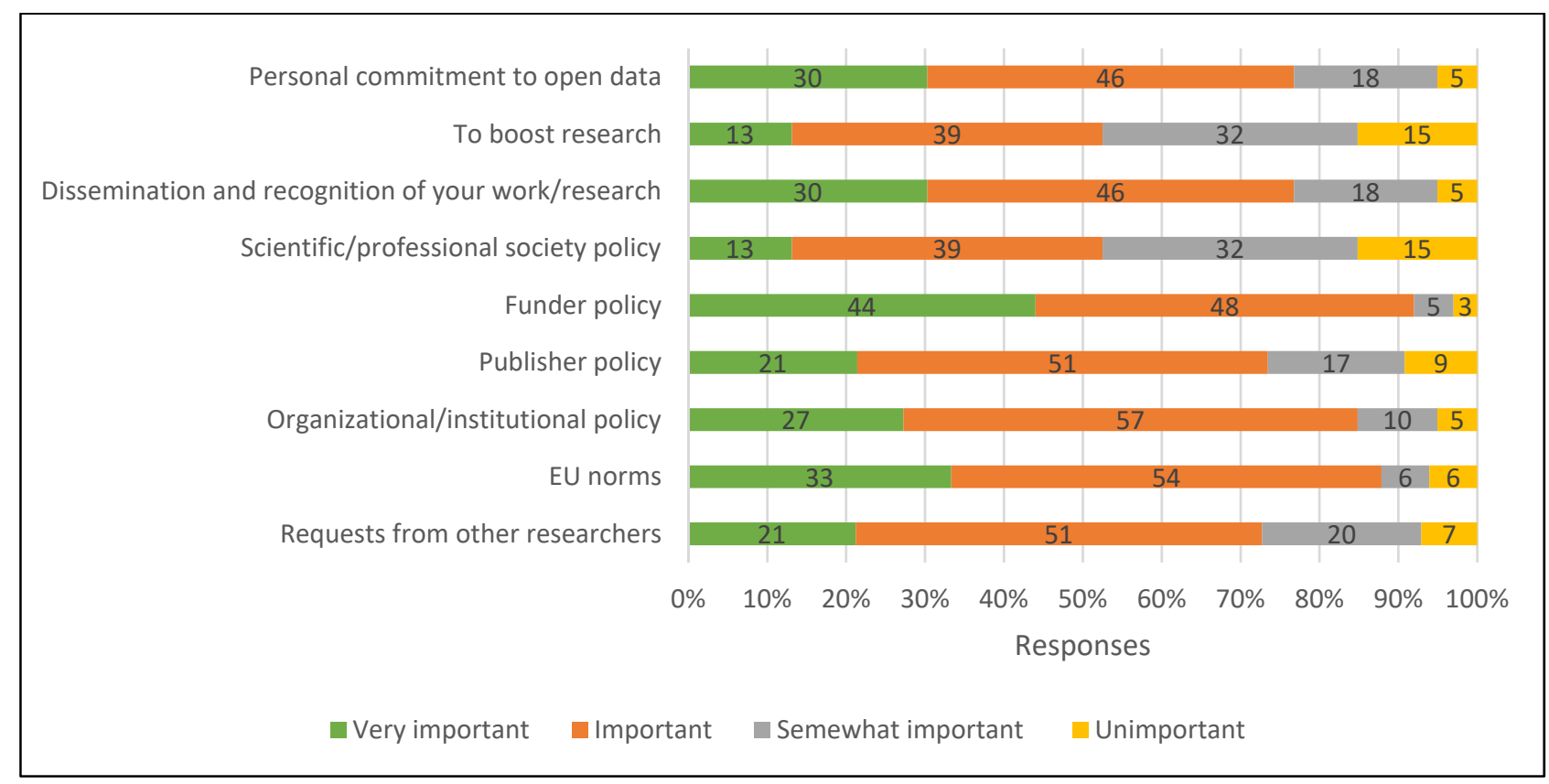

Figure 9. Important motivators to publish your data as open data (number of responses displayed in the bars). 
It is appropriate to create new datasets from shared

$$
\text { data }
$$

It is important that my data are cited when used by other researchers

I would be willing to share data across a broad group of researchers

Integrating data from various sources helps me in my research

I would be more likely to make my data available if I could place conditions on access

I would be willing to place ALL of my data into a central data repository with no restrictions

I would be willing to place at least SOME of my data into a central data repository with no restrictions

I would use other researchers' datasets if their datasets were easily accessible

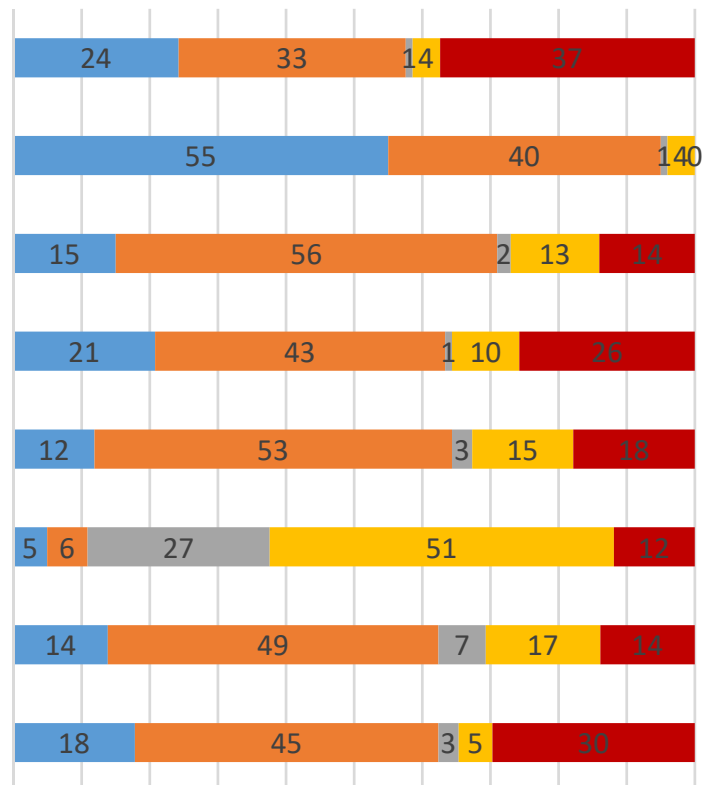

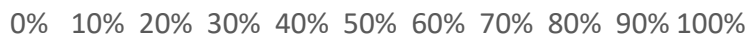

Responses

Strongly agree Agree $\square$ Neither agree nor disagree Disagree $\square$ Disagree strongly

Figure 10. Agreeement/disagreement with several statements relate to sharing scientific data (number of responses displayed in the bars). 
The possibility of protecting or restricting access to some data

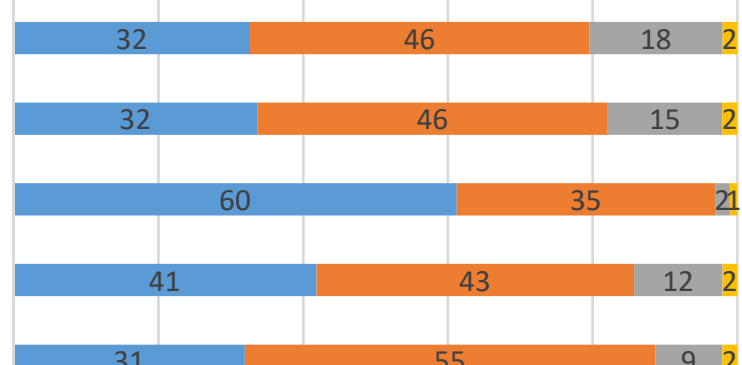

That access to the data has no cost

The potential value of the data for easy access and low cost reuse

The metadata is complete, structured according to a standard and is useful for interpreting the data

The data are clearly defined in a useful way to interpret them

Well-defined terms of use license

Possibility of reusing data for academic / research purposes

Access and use of data without restrictions
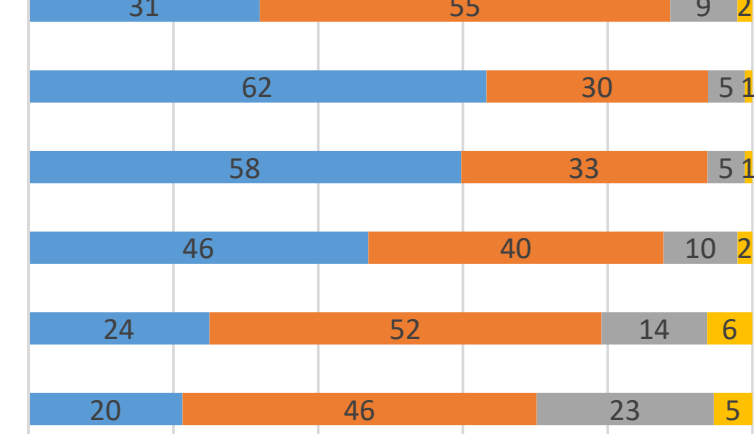

$0 \%$

$20 \% \quad 40 \%$

$60 \%$

$80 \%$

$100 \%$

Responses

- Very important

- Important

- Somewhat important

- Unimportant

Figure 11 .Importance of attributes for open data (number of responses displayed in the bars). 
Limitations on infrastructure resources

Concerns about impact of data release (e.g., on endangered species, cultural artifacts, or vulnerable populations, unwanted disclosure etc.)

Concerns about legal liability for data or release of data

Difficulty of clarifying data rights for work involving multiple inputs or authors

The potential use and commercial exploitation

Desire to publish results before releasing data

Misinterpretation or misuse of data

Loss of control over intellectual property

Loss of credit or recognition of original work

Legal constraints (data privacy, national security, protection of confidentiality, intellectual property rights etc.)

" Major Barrier $\quad$ High Barrier

$\begin{array}{llll}15 & 36 & 31 & 12\end{array}$

\begin{tabular}{l|l|l|l}
16 & 34 & 35 & 9
\end{tabular}

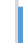

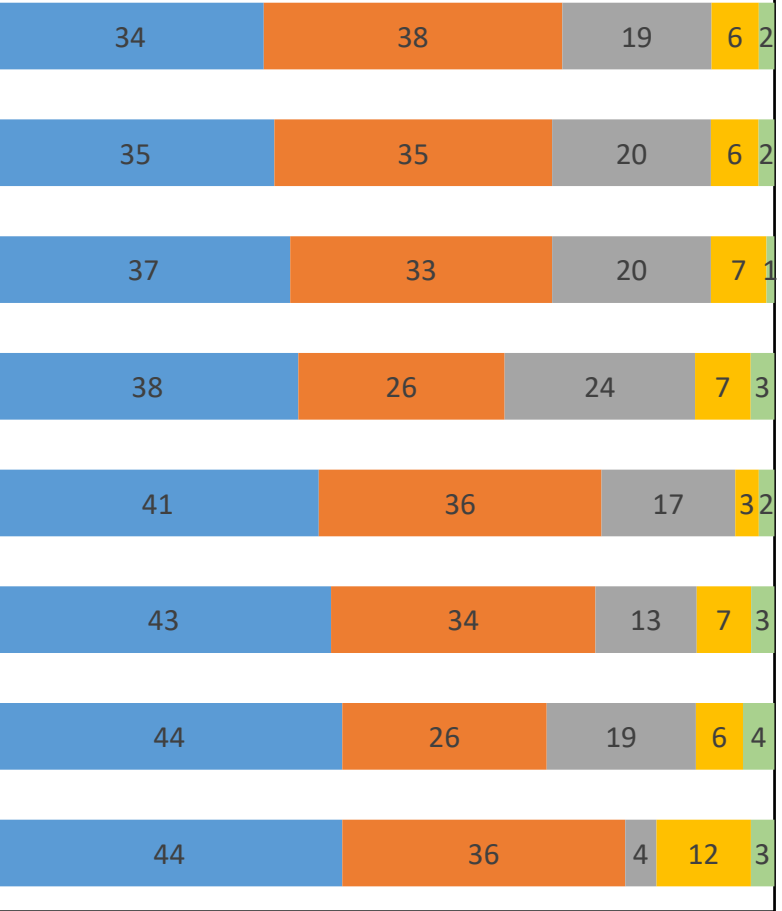

$\begin{array}{lllllllllll}0 \% & 10 \% & 20 \% & 30 \% & 40 \% & 50 \% & 60 \% & 70 \% & 80 \% & 90 \% & 100 \%\end{array}$

Half Barrier $\square$ Low Barrier $\square$ No Barrier

Figure 12. Barriers for publishing data as open data (number of responses displayed in the bars) 


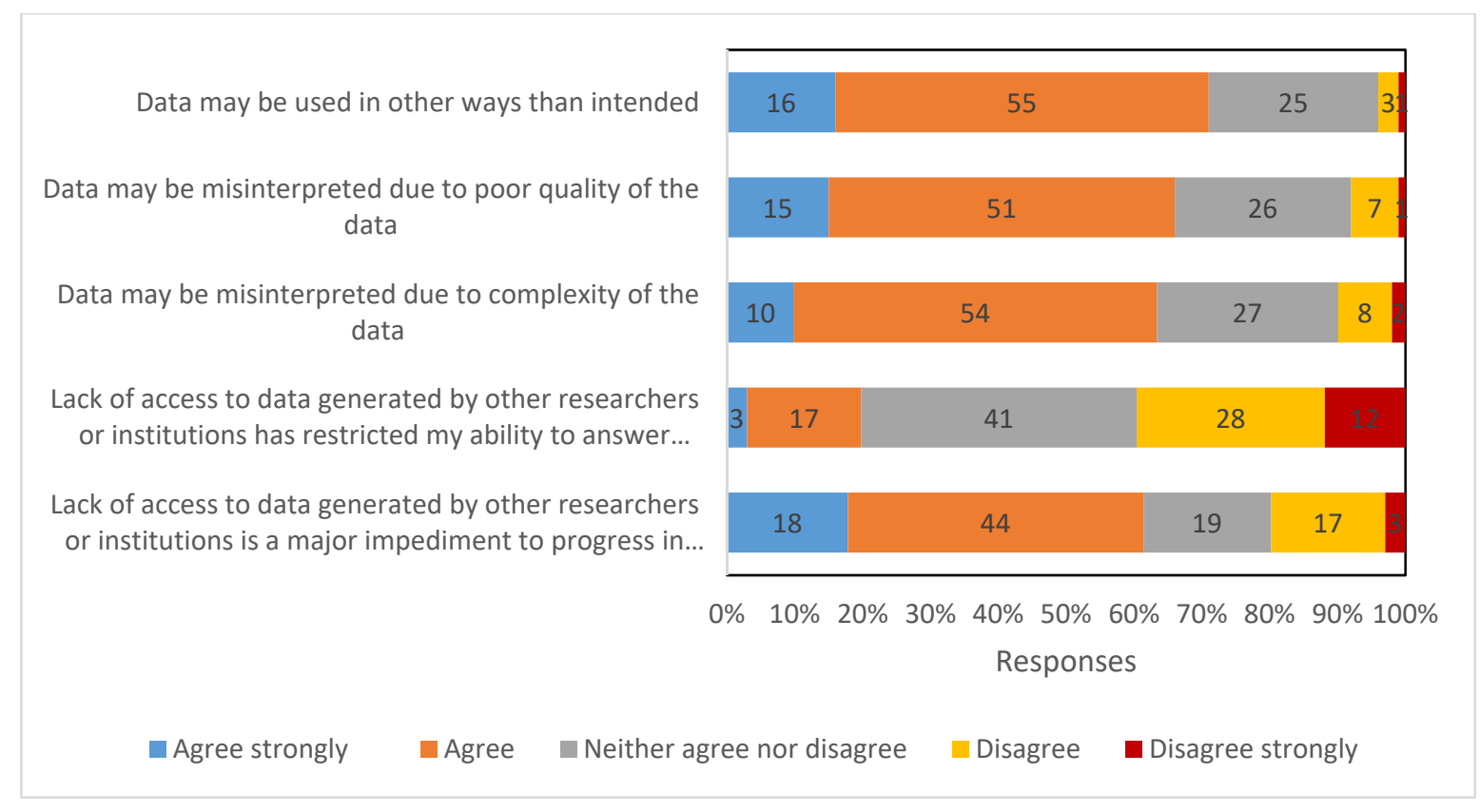

Figure 13. Views on the use of research data (number of responses displayed in the bars). 
Varying standards in how data has been gathered

Paying for data

Varying degrees of data quality in different datasets

Varying data formats

Understanding how to interpret and reuse data

Understanding how to access the data

Accessing and understanding terms of use/ licenses

Open data that are not timely available

Needing to register (e.g. in a website) to access data

Time delay between requesting and receiving data

Access information on how to cite the datasets

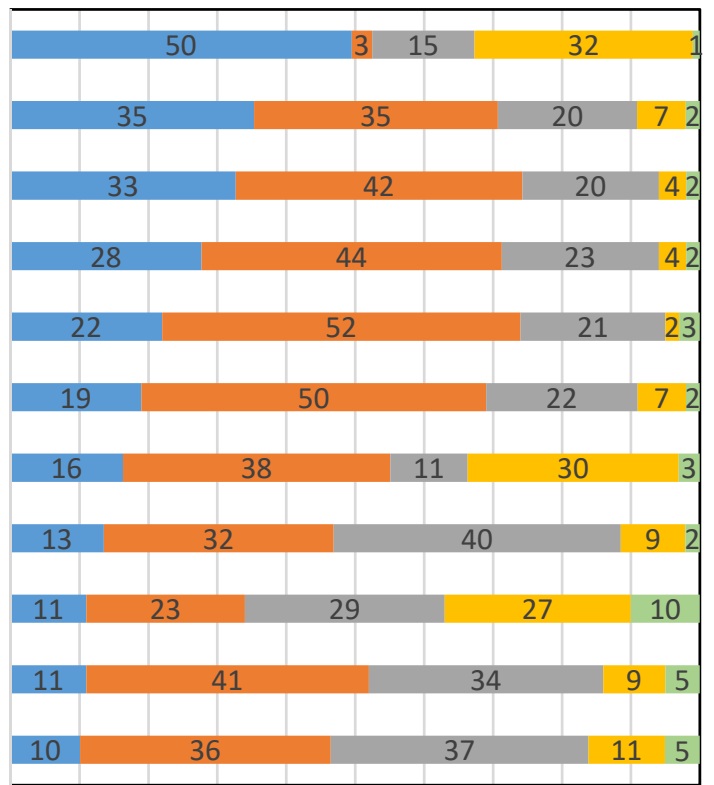

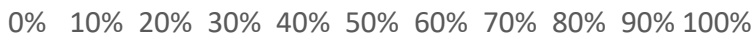

Responses

major Burden $\square$ High Burden $\square$ Half Burden $\square$ Low Burden $\quad$ No Burden

Figure 14.Significant burdens when accessing and reusing data for your work (number of responses displayed in the bars). 
TABLES

Table1. Questions about data repositories sharing and reuse of research data

\begin{tabular}{|c|c|}
\hline Question & $\%$ \\
\hline \multicolumn{2}{|l|}{ Are you aware of research data repositories? } \\
\hline I'm not sure & 12 \\
\hline No, I don't know what they are & 13 \\
\hline Yes, I am aware of research data repositories, but I have not used them & 47 \\
\hline Yes, I am already using them to find existing datasets or to share my own data & 29 \\
\hline \multicolumn{2}{|l|}{$\begin{array}{l}\text { Have you shared directly (i.e. person-to-person sharing) with others any or all of the research } \\
\text { data that you used or created as part of your last research project? }\end{array}$} \\
\hline No & 37 \\
\hline I do not know & 5 \\
\hline Yes & 57 \\
\hline \multicolumn{2}{|l|}{$\begin{array}{l}\text { Was any or all of the research data that you used or created as part of your last research } \\
\text { project shared with you by others, either directly (i.e. person-to-person) }\end{array}$} \\
\hline No & 71 \\
\hline I do not know & 4 \\
\hline Yes & 24 \\
\hline \multicolumn{2}{|l|}{ How much of your data do you make available to others? } \\
\hline Some & 55 \\
\hline Most & 29 \\
\hline None & 13 \\
\hline All & 3 \\
\hline \multicolumn{2}{|l|}{$\begin{array}{l}\text { Irrespective of public sharing (e.g. archiving your research data in a repository accessible to } \\
\text { others), have you done any of the following with any or all of the research data that you used } \\
\text { or created as part of your last research project? }\end{array}$} \\
\hline $\begin{array}{l}\text { Shared directly with researchers working on the same research project in a research } \\
\text { collaboration }\end{array}$ & 62 \\
\hline $\begin{array}{l}\text { Shared directly with researchers NOT working on the same research project who I } \\
\text { know personally }\end{array}$ & 14 \\
\hline $\begin{array}{l}\text { Shared directly with researchers NOT working on the same research project who I } \\
\text { DON'T know personally }\end{array}$ & 2 \\
\hline Shared directly with research project partners (e.g. funders) & 22 \\
\hline \multicolumn{2}{|l|}{$\begin{array}{l}\text { Prior to sharing, research data typically needs to be formatted and often has documentation } \\
\text { and/or metadata added to make it re-useable by others. How would describe the effort } \\
\text { typically required to make your research data re-useable by others? }\end{array}$} \\
\hline A lot of effort & 69 \\
\hline Some effort & 22 \\
\hline No effort & 1 \\
\hline I would not share & 8 \\
\hline
\end{tabular}


Table 2. Importance of open data and the motivators to share research.

\begin{tabular}{|c|c|c|c|}
\hline Question & & & \\
\hline \multirow{5}{*}{$\begin{array}{l}\text { OA IMPORTANCE } \\
\text { In your community, how } \\
\text { important is open data } \\
\text { to... }\end{array}$} & Option & Item & Scale \\
\hline & Research & V15 & \multirow{4}{*}{\begin{tabular}{|l} 
Very \\
Important (4) \\
Important (3) \\
Somewhat \\
important (2) \\
Not all \\
important (1)
\end{tabular}} \\
\hline & $\begin{array}{l}\text { Informative science (education, information } \\
\text { to the general public) }\end{array}$ & V16 & \\
\hline & $\begin{array}{l}\text { Supporting applications of science to societal } \\
\text { problems }\end{array}$ & V17 & \\
\hline & Technology transfer & V18 & \\
\hline \multirow{10}{*}{$\begin{array}{l}\text { MOTIVATORS TO } \\
\text { SHARING YOUR DATA } \\
\text { Which of the following are } \\
\text { important motivators to } \\
\text { publish your data as open } \\
\text { data? }\end{array}$} & Option & Item & Scale \\
\hline & Requests from other researchers & V64 & \multirow{9}{*}{$\begin{array}{l}\text { Very } \\
\text { Important (4) } \\
\text { Important (3) } \\
\text { Somewhat } \\
\text { important (2) } \\
\text { Not all } \\
\text { important (1) }\end{array}$} \\
\hline & EU norms & V65 & \\
\hline & Organizational/institutional policy & V66 & \\
\hline & Publisher policy & V67 & \\
\hline & Funder policy & V68 & \\
\hline & Scientific/professional society policy & V69 & \\
\hline & $\begin{array}{l}\text { Dissemination and recognition of your } \\
\text { work/research }\end{array}$ & V70 & \\
\hline & To boost research & V71 & \\
\hline & Personal commitment to open data & V72 & \\
\hline
\end{tabular}


Table 3. Items classified under barriers category

\begin{tabular}{|c|c|c|c|}
\hline Question & Option & Item & Scale \\
\hline \multirow{15}{*}{$\begin{array}{l}\text { What do you see as the major } \\
\text { barriers for publishing data as } \\
\text { open data? }\end{array}$} & The potential use and commercial explotation & V104 & \multirow{15}{*}{$\begin{array}{l}\text { Major Barrier (5) } \\
\text { High Barrier (4) } \\
\text { Half Barrier (3) } \\
\text { Low Barrier (2) } \\
\text { No Barrier (1) }\end{array}$} \\
\hline & Loss of control over intellectual property & V107 & \\
\hline & Misinterpretation or misuse of data & V106 & \\
\hline & Loss of credit or recognition of original work & V105 & \\
\hline & $\begin{array}{l}\text { Difficulty of clarifying data rights for work } \\
\text { involving multiple inputs or authors }\end{array}$ & V108 & \\
\hline & $\begin{array}{l}\text { Concerns about legal liability for data or release of } \\
\text { data }\end{array}$ & V103 & \\
\hline & $\begin{array}{l}\text { Concerns about impact of data release (e.g., on } \\
\text { endangered species, cultural artifacts, or } \\
\text { vulnerable populations, unwanted disclosure etc.) }\end{array}$ & V109 & \\
\hline & Varying data formats & V124 & \\
\hline & Varying standards in how has been gathered & V123 & \\
\hline & $\begin{array}{l}\text { Varying degrees of data quality in different } \\
\text { datasets }\end{array}$ & V122 & \\
\hline & Understanding how to interpret and reuse data & V121 & \\
\hline & Access information on how to cite the datasets & V119 & \\
\hline & $\begin{array}{l}\text { Accessing and understanding terms of use/ } \\
\text { licenses }\end{array}$ & V118 & \\
\hline & $\begin{array}{l}\text { Needing to register (e.g. in a website) to access } \\
\text { data }\end{array}$ & V117 & \\
\hline & Understanding how to access the data & V120 & \\
\hline
\end{tabular}


Table 4. Items associated with which conditions would they share their data or would facilitate their access

\begin{tabular}{|c|c|c|c|}
\hline Question & Option & Item & Scale \\
\hline \multirow{12}{*}{$\begin{array}{l}\text { CONDITIONS TO } \\
\text { SHARING YOUR } \\
\text { DATA } \\
\text { The following } \\
\text { statements relate } \\
\text { to conditions for } \\
\text { use of your data. } \\
\text { Indicate whether } \\
\text { you agree or } \\
\text { disagree with each } \\
\text { condition. }\end{array}$} & $\begin{array}{l}\text { Should be co-authorship on publications resulting } \\
\text { from use of the data. }\end{array}$ & V39 & \multirow{12}{*}{$\begin{array}{l}\text { Yes (2) } \\
\text { I am not sure (1) } \\
\text { No (0) }\end{array}$} \\
\hline & $\begin{array}{l}\text { Acknowledgement of the data providers in all } \\
\text { disseminated work making use of the data. }\end{array}$ & V40 & \\
\hline & $\begin{array}{l}\text { Citation of the data providers in all disseminated } \\
\text { work making use of the data. }\end{array}$ & V41 & \\
\hline & $\begin{array}{l}\text { Share facilitates the opportunity to collaborate on a } \\
\text { project using the data. }\end{array}$ & V42 & \\
\hline & $\begin{array}{l}\text { The results based (at least in part) on the data could } \\
\text { not be disseminated in any format without the data } \\
\text { provider's approval. }\end{array}$ & V43 & \\
\hline & $\begin{array}{l}\text { At least part of the costs of data acquisition, retrieval } \\
\text { or provision must be recovered. }\end{array}$ & V44 & \\
\hline & $\begin{array}{l}\text { The results based (at least in part) on the data could } \\
\text { not be disseminated without the data provider } \\
\text { having the opportunity to review the results and } \\
\text { make suggestions or comments, but approval not } \\
\text { required. }\end{array}$ & V45 & \\
\hline & $\begin{array}{l}\text { Reprints of articles that make use of the data must } \\
\text { be provided to the data provide }\end{array}$ & V46 & \\
\hline & $\begin{array}{l}\text { The data provider is given a complete list of all } \\
\text { products that make use of the data, including } \\
\text { articles, presentations, educational materials, etc. }\end{array}$ & V47 & \\
\hline & Legal permission for data use is obtained & V48 & \\
\hline & $\begin{array}{l}\text { There is a mutual agreement on reciprocal sharing of } \\
\text { data }\end{array}$ & V49 & \\
\hline & $\begin{array}{l}\text { The data provider, provides and accepts an } \\
\text { agreement for its use. }\end{array}$ & V50 & \\
\hline \multirow{8}{*}{$\begin{array}{l}\text { MOTIVATORS } \\
\text { TO USING AND } \\
\text { SHARING DATA } \\
\text { The following } \\
\text { statements relate } \\
\text { to sharing } \\
\text { scientific data. Tell } \\
\text { us how much you } \\
\text { agree with each } \\
\text { statement. }\end{array}$} & $\begin{array}{l}\text { I would use other researchers' datasets if their } \\
\text { datasets were easily accesible. }\end{array}$ & V73 & \multirow{8}{*}{$\begin{array}{l}\text { Agree strongly (5) } \\
\text { Agree (4) } \\
\text { Neither agree nor } \\
\text { disagree (3) } \\
\text { Disagree (2) } \\
\text { Disagree strongly (1) }\end{array}$} \\
\hline & $\begin{array}{l}\text { I would be willing to place at least SOME of my data } \\
\text { into a central data repository with no restrictions. }\end{array}$ & V74 & \\
\hline & $\begin{array}{l}\text { I would be willing to place ALL of my data into a } \\
\text { central data repository with no restrictions. }\end{array}$ & V75 & \\
\hline & $\begin{array}{l}\text { I would be more likely to make my data available if I } \\
\text { could place conditions on Access. }\end{array}$ & V76 & \\
\hline & $\begin{array}{l}\text { Integrating data from various sources helps me in } \\
\text { my research. }\end{array}$ & V77 & \\
\hline & $\begin{array}{l}\text { I would be willing to share data across a broad group } \\
\text { of researchers. }\end{array}$ & V78 & \\
\hline & $\begin{array}{l}\text { It is important that my data are cited when used by } \\
\text { other researchers. }\end{array}$ & V79 & \\
\hline & $\begin{array}{l}\text { It is appropriate to create new datasets from shared } \\
\text { data. }\end{array}$ & V80 & \\
\hline
\end{tabular}


Table 5. Items affecting the quality of the metadata and attributes of the research data

\begin{tabular}{|c|c|c|c|}
\hline Question & \multirow[t]{2}{*}{ Option } & \multirow[t]{2}{*}{ Item } & \multirow[t]{2}{*}{ Scale } \\
\hline \multirow{9}{*}{$\begin{array}{l}\text { How important were the } \\
\text { following factors when } \\
\text { deciding to use others' } \\
\text { research data that the data }\end{array}$} & & & \\
\hline & $\begin{array}{l}\text { Are from someone I DON'T know personally } \\
\text { but who has a good reputation }\end{array}$ & V52 & \multirow{8}{*}{$\begin{array}{l}\text { Very } \\
\text { Important (4) } \\
\text { Important (3) } \\
\text { Somewhat } \\
\text { important (2) } \\
\text { Not all } \\
\text { important (1) }\end{array}$} \\
\hline & $\begin{array}{l}\text { Are from someone at an institute with a good } \\
\text { reputation }\end{array}$ & V53 & \\
\hline & Are from a repository with a good reputation & V54 & \\
\hline & $\begin{array}{l}\text { Comply with guidelines around collection } \\
\text { and/or formatting }\end{array}$ & V55 & \\
\hline & Have good documentation and/or metadata & V56 & \\
\hline & Are certified or accredited by a third party & V57 & \\
\hline & Are commonly used by others & V58 & \\
\hline & $\begin{array}{l}\text { Have been cited in a publication in the formal } \\
\text { literature (journals, books, etc.) }\end{array}$ & V59 & \\
\hline Which attributes do you & Access and use of data without restrictions & V81 & \\
\hline $\begin{array}{l}\text { think are most important } \\
\text { to open data? }\end{array}$ & $\begin{array}{l}\text { Possibility of reusing data for academic / } \\
\text { research purposes }\end{array}$ & V82 & $\begin{array}{l}\text { Very } \\
\text { Important (4) }\end{array}$ \\
\hline & Well-defined terms of use license & V83 & Important (3) \\
\hline & $\begin{array}{l}\text { The data are clearly defined in a useful way to } \\
\text { interpret them }\end{array}$ & V84 & $\begin{array}{l}\text { Somewhat } \\
\text { important (2) }\end{array}$ \\
\hline & $\begin{array}{l}\text { The metadata is complete, structured } \\
\text { according to a standard and is useful for } \\
\text { interpreting the data }\end{array}$ & V85 & $\begin{array}{l}\text { Not all } \\
\text { important (1) }\end{array}$ \\
\hline & $\begin{array}{l}\text { The potential value of the data for easy access } \\
\text { and low cost reuse }\end{array}$ & V86 & \\
\hline & That access to the data has no cost & V87 & \\
\hline & Data are updated & V88 & \\
\hline & Data are recent & V89 & \\
\hline
\end{tabular}

